who live alone have more in common with married people, in terms of mental health, than unmarried people who live with others. These data suggest that unmarried people who live alone are more likely than unmarried people who live with others to engage in drug or alcohol use.

In conclusion, Hughes and Gove argue that living alone is not particularly problematic; a finding which raises serious questions about social integration theory. They argue that many of the effects normally attributed to social integration may not be a consequence of close, intimate, warm social relationships, but simply a consequence of social control. They also argue that such relationships can have negative effects and therefore costs. Thus socially integrated relationships not only provide direct social rewards through reinforcement and increased meaning to life but also incur costs in the form of social constraint, obligation and responsibility.

\title{
COMMENT
}

This article is useful in a number of ways. First, it looked at another old chestnut as to whether social isolation causes mental illness or whether people with mental illness tend to live alone. As I have reported they show that there is no evidence that people who live alone are selected into that living arrangement because of pre-existing psychological problems. Second, the article is useful because it challenges traditional sociological theory on the nature of social integration. As a heuristic device I found the article fairly challenging but felt that the ideas presented in the discussion were somewhat confusing, and I am not convinced that they have fully substantiated their criticisms of the theory. However, this article will certainly encourage me to look more closely at social integration theory in the future.

Health Care Research Unit,

University of Newcastle.

\section{Social Services}

\section{John E. Tibbitt}

Heumann, L. F., 'The function of different sheltered housing categories for the semi-independent elderly', Social Policy and Administration, 15.2, Summer 198I, pp. 164-80.

Sheltered housing is now well established as a key element in the range of accommodation available for the elderly. The rage is often thought of as 
a continuum from conventional family housing, through sheltered accommodation to institutional care in an old people's home or hospital. In England and Wales, though not in Scotland, sheltered housing is itself officially divided into category I and category II housing, the former intended for old people of a 'more active kind' and the latter for the less active. However it is now being questioned whether the official definitions of these categories are sufficient to be able to distinguish between levels of activity and functional ability among elderly residents. There are some critics who claim that some category I schemes are more appropriate for the less active elderly than is category II housing.

This paper addresses a number of questions arising from an investigation of such claims. It examines the role and services actually provided by different sheltered housing schemes in a random sample of thirty-four category I and II schemes operated by voluntary associations and public agencies in the English Midlands. Data on the socio-economic, demographic, health, activity and movement patterns of 1516 elderly residents were collected from the wardens' records, and structured interviews were conducted with the management and the wardens of the schemes to explore policies and patterns of allocation and movement of residents into and out of particular schemes.

Most managers were attempting to maintain a balance of more and less active people in each scheme regardless of its category. In seeing both category I and category II as housing people from a similar activity range, many saw the need for an additional category (categoryII $\frac{1}{2}$ or 'very sheltered housing') which could accommodate less active people than either I or II. The residents of the schemes were compared on a number of variables such as age, number of disabilities, mobility, and activities of daily living. Overall, category II housing contained a consistently higher proportion of less active and more frail residents.

In an interesting concluding section, several useful observations are made on the role of sheltered housing, on the extent to which it can be located in a continuum of care, and on the value of distinguishing category I and category II housing. The author suggests that the variety of housing types do not represent a continuum on which individuals are transferred as needs change, but do represent a continuum of entry points from unsupported accommodation. Category I and II, as currently defined, may represent different choices in communal living and life style rather than housing appropriate to different levels of functional ability. A few changes in definition and design criteria could strengthen the distinctions between the categories in this latter regard too. 
This is a real contribution to the growing literature on sheltered housing, particularly in the insights it provides into admissions policies and constraints on movement of residents into and out of the various types of sheltered accommodation. It is less successful in its measures of resident characteristics - many of the variables are rather rudimentary, and some measures are of questionable validity. Also, the study is a cross-sectional study of residents at one point in time. Many of the schemes surveyed were very new. As time passes the characteristics of schemes may well change as residents become increasingly frail. Nevertheless, the implications of the observations offered deserve serious consideration by all involved in the planning, managing, and day-to-day running of sheltered housing schemes.

Butler, Alan, 'Dispersed Alarm Systems for the Elderly', Social Work Service, No. 25, January 1981.

This paper was prompted by the widespread interest in the installation of alarms for the elderly which the author detected in the course of conducting research on sheltered housing in England and Wales. He observed that authorities frequently ignored the fundamental questions of why alarms were needed and what they were to do before giving consideration to the type of alarm to be installed. The paper is concerned with three topics: first, it examines some reasons for the expansion of dispersed alarm systems for the elderly; second it raises some basic questions about why the alarms are provided; and finally it discusses issues relating to the place of alarms in the wider field of the care of the elderly.

Many varieties of alarm system are now available ranging from simple mechanical devices such as flashing lights or signs outside the old person's house to technologically much more sophisticated systems which utilize small radio receivers and transmitters or make use of the existing telephone network. Butler detects something of a 'new toy' syndrome in some local authorities in their approach to the installation of new alarm systems. Other reasons for the spread of these systems include the attempt to extend the concept of sheltered housing to mainstream housing, the need to relieve the excessive workloads of the wardens' of sheltered housing schemes, and the need to be seen to be providing some protection for increasing numbers of elderly people in the face of cutbacks in the availability of other more 'traditional' resources. 
Butler argues that the effective use of a resource which can involve a substantial capital outlay depends upon the accurate prediction of who is most at risk, and this in turn depends on an efficient assessment and allocation procedure. There is a body of research findings which indicates that many people who currently have alarms do not use them in the emergencies they experience, and other research suggests that alarms are marginal to the lives of sheltered housing tenants. Alarms would not appear to be the panacea claimed by many manufacturers, and further research is required on the effect of installation on patterns of social interaction.

The author concludes with some practical points which authorities need to consider if they are to select an efficient alarm system appropriate to their needs. He points to the need for more sharing of information about the performance of alternative systems, the need to involve existing staff in the operation of the alarm system, and above all, the need for greater dialogue with the elderly consumers.

\section{COMMENT}

This paper is a timely reminder of a number of essentially operational issues involved with the utilization of dispersed alarm systems. It should alert agencies to the dangers of being seduced by the technological dazzle of many of the products on the market. Agencies should clarify the role they require of an alarm system rather than wondering how they can use the products' manufacturers are pressing upon them.

Challis, D. J., 'The Measurement of Outcome in Social Care of the Elderly', Fournal of Social Policy, 10.2, pp. 179-208.

The measurement of the outcomes of interventions by social services departments and other agencies providing social care for the elderly is one of the key problems for research into the effectiveness of these services. Outcome measurement is still at an early stage of development and this paper is a contribution towards a consensus among researchers about methods by which this might be achieved. It is concerned primarily with two tasks: first, the deliniation of appropriate policy objectives for the interventions, and second, the development of tools of measurement appropriate to these objectives.

Challis argues that the literature of social administration, social work and government policy consistently points to seven dimensions upon which 
the effects of services may be assessed. These he calls nurturance, compensation for disability, independence, morale, social integration, family relationships, and community development. The bulk of the paper is taken up with the explication and discussion of literature relating to the operationalisation of these dimensions. It is a densely argued and comprehensive review. Its 172 references span both British and American sources, and highlight the very real problems of bringing together the very large number of disparate attempts to develop and validate suitable measures. The need for studies of social care to move towards employing similar criteria of measurement if valid comparisons of different kinds of intervention are to be made is abundantly clear.

\section{COMMENT}

The author has performed a valuable service in bringing together in such a succinct way such a diverse literature. Whether or not the paper will achieve its objective of contributing towards the development of a degree of consensus on measures to be used may be more doubtful. What the paper does do is to throw into stark relief the complexity of the task facing an evaluator of social care. This is brought home all the more strongly when it is remembered that it is concerned only with measures of deliberate and intended consequences of an intervention programme, and does not tackle other crucial areas such as the unintended consequences of care, the relative importance to be attached to the various dimensions, and problems of who involved in the social care process subscribes to which dimension, and when.

Monk, Abraham, 'Social Work with the aged: principles of practice', Social Work, 26.I, January 1981, pp. 6 I-8.

This paper, written by a professor of gerontology, is one contribution in a special edition of Social Work, the journal of the National Association of Social Workers in the US, concerned with conceptual frameworks in social work. It is less a report of research, being more of a theoretical discussion of the purpose of social work in relation to the elderly.

Monk begins by exploring three perspectives on ageing which may present difficulties for the social worker. The first of these arises from a view of the uniqueness of old age as the phase in life when individuals have to complete the integration of their experiences and the closure of experience on death. It is argued that social workers, many of whom are 
relatively young, will have a very different view of time as an inexhaustible commodity, and may have very little concept of a 'time left to live' or of the need to take stock of accomplishments and unfulfilled aspirations. Social workers are usually interested in personal growth. With respect to the elderly, they have to work with the remaining strengths as these are successively reduced by chronic impediments and functionary losses.

The second perspective derives from a view of the elderly as a low status group for whom nothing very exciting can be done and for whom the provision of substantial resources may not be worthwhile. This low status may reflect on those who work with the elderly, and may create a danger for social work, reinforcing stereotyped beliefs and, in turn, leading to a depersonalized service.

The third perspective arises from the implications of demographic change for the relationships between generations and for the allocation of responsibility for the care of an ever larger and more frail proportion of the population. It is clearly unrealistic to expect that the public services can assume care for a whole age group but there may be a role for social work in co-ordinating and seeking to influence the delivery of a whole variety of social services which collectively contribute to the welfare of the elderly.

The paper then discusses at some length styles of work for social work and social work objectives based on the implications of these perspectives. It is argued that many of the conventional statements of the purposes of social work, frequently based on terms such as 'productivity', 'effective contributions', or 'maximizing growth potential' do not apply. Rather the emphasis should be on helping people to increase their coping abilities, obtain resources, making organizations more responsible to individual needs, and influencing social and environmental policy.

\section{COMMENT}

The social work profession has struggled hard to define its tasks and roles in terms which are readily understood by those outside the profession. This attempt, grounded as it is in a broad social gerontological approach, might be more successful than many others. In a relatively short space a context is provided for a listing of a considerable number of more or less practical statements of the approach social workers might profitably take with elderly clients.

\section{Social Work Services Group}

Edinburgh 